\title{
GESTÃO DE PROJETOS DE
}

\section{ARQUITETURA E ENGENHARIA}

\section{COM O ERP/CRM CUSTOMIZADO - \\ CUBO PLAN}

$\begin{array}{ll}\text { Recebido em } & 25.11 .2017 \\ \text { Aprovado em } & 12.12 .2017\end{array}$

\section{Eduardo Velo de Oliveira}

Diretor da área de desenvolvimento de novos projetos e negócios e sócio-fundador da Tetra Projetos, é arquiteto pelo Mackenzie. Criador do ERP Cubo Plan para a gestão de projetos de arquitetura e engenharia civil. E-mail: eduardo@tetraprojetos.com.br

\section{Gustavo André Matheus Vaz de Lima}

Consultor de negócios, engenheiro pela Unicid, atua com criação de soluções para a operação de serviços gerenciados no setor de infraestrutura de telecomunicações para projetos no Brasil. E-mail: gamvazdelima@gmail.com

\section{Samuel Aguiar de Castro e Souza}

Consultor do Sebrae-SP em gestão e planos de marketing, formado em Administração de Empresas pelo Mackenzie. É professor convidado na FMU, nos cursos de Comunicação e Marketing, e Marketing e Estratégia Digital. 


\section{Reynaldo Cavalheiro Marcondes}

Professor titular do Centro de Ciências Sociais e

Aplicadas da Universidade Presbiteriana

Mackenzie, docente permanente do Programa de

Mestrado Profissional em Administração do

Desenvolvimento de Negócios.

E-mail: reynaldo.marcondes@mackenzie.br

\section{Marcus Paulo Linares Rodrigues}

Consultor de operações estratégicas voltadas a TI e

Processos Ágeis. Formado em Sistemas de Informação pelo Mackenzie, é professor de pós-graduação em cursos de gestão estratégica de vendas e gestão estratégica de negócios.

E-mail:mplinares@gmail.com

\section{Glauber Rodrigues Pereira}

Gestor administrativo/financeiro da rede de Lojas

Bunny's. É graduado em Administração pela

Faculdade Católica do Tocantins.

E-mail:admglauber@hotmail.com

\section{RESUMO}

Este relato apresenta o desenvolvimento do sistema ERP/CRM Cubo Plan da empresa Tetra Arquitetura, que identificou como oportunidade de mercado atender a demandas de escritórios de projetos de arquitetura e engenharia civil, oferecer uma ferramenta para gerar informações integradas e capazes de acompanhar e avaliar o desempenho dos seus negócios. A ausência de ferramentas específicas de informações para a gestão da própria empresa resultou no desenvolvimento de um sistema para melhorar o controle efetivo dos seus processos. De fato, as informações para garantir a eficiência dos projetos executados pela empresa ficavam distribuídas por diversas bases e plataformas, causando um elevado volume de trabalho em algo que não era o seu core business, prejudicando a tomada de decisões. Assim, partiu-se da experiência interna com a utilização da ferramenta, para depois oferecê-la ao mercado de projetos de arquitetura e engenharia civil, dando origem a um novo negócio. Este relato apresenta os detalhes do que foi feito para se desenvolver e lançar o sistema ERP/ CRM Cubo Plan como um produto diferenciado no mercado, com base em uma metodologia para a elaboração de trabalhos práticos e aplicados.

\section{PALAVRAS-CHAVE}

ERP/CRM. Gestão de Projetos. Sistema de Gestão. Cubo Plan. 


\section{INTRODUÇÃO}

O objetivo deste trabalho é apresentar o desenvolvimento de um projeto para aproveitamento da oportunidade de um negócio identificado pela empresa Tetra Arquitetura. É consequência de desafios enfrentados na gestão da própria empresa na execução de projetos junto aos seus clientes. Diante disso, buscou-se no mercado de software uma solução ERP que pudesse atender as suas necessidades. Após uma pesquisa nos principais fornecedores de software de gestão, verificou-se que as ferramentas propostas no mercado não atendiam suas expectativas, nem pelo que oferecia de benefícios, nem pelo valor que a Tetra Arquitetura estava disposta a pagar. Diante disso, aventou-se a possibilidade de a própria empresa iniciar internamente o desenvolvimento de um sistema customizado. Em seu quadro permanente de colaboradores a empresa contava com um programador de sistemas que desenvolveu grande parte da linguagem do programa. O sistema está sendo desenvolvido desde 2009 e tem se mostrado eficiente na gestão da Tetra Arquitetura e de alguns clientes tradicionais. Com isso, a empresa entendeu que poderia oferecer esse sistema para diversas outras empresas que possuíssem o core business similar ao seu.

Em reunião de diretoria ficou decidido criar-se um negócio independente para a venda do sistema como um produto, denominado Cubo Plan.

Até meados de junho de 2017 houve um investimento de aproximadamente $\mathrm{R} \$ 140.000,00$ para o desenvolvimento do sistema, com a intenção de atender o mercado de projetos e gestão de contratos para as áreas de arquitetura e engenharia civil.

Para isso, foram realizadas entrevistas com os próprios funcionários da Tetra Arquitetura e com arquitetos, engenheiros externos à empresa, para conhecer com maior profundidade os resultados da sua aplicação na gestão dos projetos, no mercado em que atuam. Ferramentas como Canvas, Análise Swot, Ciclo PDCA foram utilizadas para confirmar a oportunidade do mercado e realizar as melhorias no produto. Também foram realizadas observações nos concorrentes do sistema para identificar as suas limitações, e ainda como o Cubo Plan poderia aplicar grandes diferenciais para se destacar no mercado. Os resultados obtidos apontaram para a satisfação dos requisitos e expectativas dos potenciais clientes. 
Hoje a Cubo Plan se prepara para entrar no mercado, com homologação por parceiros estratégicos e um posicionamento claro.

A estratégia de inserção no mercado prevê a realização de parcerias com universidades para que os estudantes de arquitetura e engenharia civil possam se familiarizar com o sistema e divulgá-lo no mercado. Espera-se o retorno do investimento após 24 meses, a partir do qual esperam-se o início dos lucros e a preparação para novos investimentos, como aplicativo móvel para melhor gestão individual e a entrada em novos segmentos para esse negócio.

\section{CONTEXTO E REALIDADE INVESTIGADA}

O mercado de arquitetura é amplo, ocorrendo intensa competição tanto entre grandes escritórios de projetos arquitetônicos como com profissionais liberais e individuais. A empresa Tetra Arquitetura foi fundada em 2005 por Arno Hadlich, Marc Duwe e Eduardo Velo, com o objetivo de preencher a lacuna de equipes de arquitetura nas grandes empresas de engenharia civil, especificamente no projeto da Linha 4 - Amarela do Metrô de São Paulo. Hoje, além dos projetos de metrô, a empresa vem se destacando nas áreas de transportes, como corredores e terminais de ônibus, áreas esportivas, como estádios, além de projetos industriais e institucionais.

Contando com profissionais com reputação de muitos anos na criação de projetos de alto nível, a Tetra Arquitetura está capacitada para a criação de uma arquitetura de qualidade, atendendo aos pré-requisitos técnicos, procurando mesclar técnica e arrojo em seus projetos. Prioriza o cliente, une e valoriza conforto, beleza, sustentabilidade, forma e inovação em uma arquitetura de alto desempenho, procurando agregar valor a cada novo desafio.

A empresa atua em um nicho de mercado voltado para obras de grandes dimensões com impacto urbano, tendo como clientes o governo e a iniciativa privada, além de parcerias entre ambos. É vital para o seu desenvolvimento e sustentabilidade o relacionamento com grandes construtoras e incorporadoras.

\section{ERP para a gestão de projetos de arquitetura}

Conhecido como ERP (do inglês Enterprise Resource Planning), trata-se de um 
sistema de informação que integra todos os dados e processos de uma organização em um único sistema. A integração pode ser vista sob a perspectiva funcional (sistemas de finanças, contabilidade, recursos humanos, fabricação, marketing, vendas e compras) e sob a perspectiva sistêmica (sistema de processamento de transações, sistemas de informações gerenciais e sistemas de apoio à decisão). É uma plataforma de software desenvolvida para integrar os diversos departamentos de uma empresa, possibilitando a automação e o armazenamento de todas as informações do negócio.

A gestão e administração de projetos de arquitetura e grandes obras de infraestrutura enfrenta diversos desafios operacionais e de controle financeiro justamente por suas complexidades técnicas e períodos longos de implementação, o que justifica investimento em ferramentas e processos de gestão automatizados.

\section{Análise de mercado de ERP para o setor de arquitetura}

Para confirmar a oportunidade mencionada anteriormente, foi realizada uma pesquisa preliminar sobre a disponibilidade de ferramentas de TI no mercado que pudessem atender às necessidades da Tetra Arquitetura, mas os resultados iniciais não foram satisfatórios pelos seguintes motivos:

- Especificações técnicas de arquitetura: o mercado oferecia ferramentas que não aceitavam customizações para atender o setor de arquitetura.

- Custo/benefício desfavorável, pois as ferramentas que poderiam atender a empresa não estavam dentro das expectativas de valor de investimentos nesse tipo de recurso.

\section{sistema ERP Cubo Plan}

Com o crescimento da empresa e a diversidade dos serviços, a Tetra Arquitetura identificou que precisava melhorar a maneira da gestão dos projetos e contratos durante a execução de suas entregas de serviços. Mediante uma iniciativa interna, optou-se por desenvolver internamente um sistema ERP dedicado às necessidades da arquitetura e projetos de grande porte. Assim, foi iniciado o desenvolvimento do ERP Cubo Plan como uma excelente oportunidade de desenvolvimento de um negócio com este produto.

O ERP Cubo Plan oferece os seguintes recursos, entre os mais impactantes: 
- Identificação dos projetos lucrativos e deficitários.

- Linha do tempo da execução do projeto: implantação $x$ planejado.

- Gestão financeira de cada projeto: pendências de recebimentos de clientes, receitas e despesas.

- Unificação das informações, eliminando diferentes documentos para os mesmos processos.

- Disponibilização de informações para tomada de decisões estratégicas, com base na ferramenta Dashboard.

- Visão clara e objetiva sobre o conjunto do projeto.

\section{DIAGNÓSTICO DA OPORTUNIDADE}

Após o desenvolvimento interno da ferramenta Cubo Plan, iniciaram-se os testes efetivos na própria empresa Tetra Arquitetura e em empresas parceiras. Arquitetos e engenheiros consultados apontaram a Cubo Plan como uma ferramenta eficiente e eficaz no trato com controles gerenciais. Essa constatação foi verificada posteriormente como diferencial no mercado de arquitetura, capaz de gerar demanda para quem não dispõe de um sistema prático de gestão de projetos. Esse resultado foi o primeiro indicativo da oportunidade de desenvolvimento de negócios.

Para verificação mais profunda da oportunidade, pesquisas foram realizadas junto a escritórios parceiros e clientes da Tetra Arquitetura, além de profissionais autônomos. Procurou-se avaliar a eficiência e eficácia da ferramenta nas atividades cotidianas, para entender a percepção da sua efetiva criação de valor, tanto para uso próprio como para monitoramento da equipe de trabalho, acompanhamento de marcos críticos e execução orçamentária dos projetos.

Para caracterizar melhor as necessidades do mercado de gestão de projetos de arquitetura e engenharia civil, algumas ações foram desenvolvidas e estão apresentadas na próxima seção.

\section{DESENVOLVIMENTOS SUBSEQUENTES}

Inúmeras ações foram realizadas para a confirmação da oportunidade de desenvolvimento da ferramenta Cubo Plan, tendo em vista recuperar o valor investido em 24 meses e obter fontes de receitas que 
atendessem as expectativas dos gestores desse negócio, conforme seguem:

- Brainstorm com equipe interna da empresa Tetra Arquitetura e da Cubo Plan.

- Pesquisa 1 - análise de satisfação do funcionário da empresa com a ferramenta Cubo Plan.

- Pesquisa 2 - análise do desempenho de outras ferramentas concorrentes do Cubo Plan.

- Pesquisa 3 - análise do ponto de vista de outros arquitetos e engenheiros.

- Aplicação do modelo Canvas.

- Aplicação do ciclo PDCA e da análise Swot.

- Proposta de aproveitamento de oportunidades.

- Plano das principais ações.

- Matriz de avaliação de riscos.

\section{Brainstorm interno}

Durante as reuniões com os fundadores e corpo diretivo da Tetra Arquitetura diversas questões foram levantadas de maneira a explorar a potencialidade da ferramenta e suas funcionalidades. Seguem as sínteses das respostas às perguntas formuladas:

A. Qual fatia do mercado não está bem atendida?
A maioria das empresas de arquitetura não possui um software ERP para acompanhar/avaliar os resultados de seus contratos. As que possuem não estão satisfeitas com os ERP contratados, por não permitirem a customização necessária para o mercado de arquitetura, tornando a ferramenta engessada para a sua utilização. As empresas de arquitetura estão descontentes com os softwares contratados por não terem fácil visualização do que eles necessitam na gestão de contratos.

B. Qual fatia do mercado está atendida? Algumas empresas não se preocupam com software de gestão de contratos e preferem ficar com suas planilhas, mesmo tendo altos riscos de não estarem realizando a gestão de maneira eficiente. Alguns contratos dão altos índices de prejuízo, mas são mascarados por outros contratos que dão lucro dentro da empresa.

c. Em que aspecto o produto se diferencia dos concorrentes?

O Cubo Plan tem destaque por ser um produto $100 \%$ gráfico com análise intuitiva, enquanto os demais carecem de ferramentas eficientes para que o gestor consiga tomar decisões eficientes e 
eficazes. Essa ferramenta gera mais informações sobre resultados estratégicos para as empresas. Facilita às pessoas que não detêm grande experiência em gestão de empresas a tomarem decisões estratégicas relevantes. O Cubo Plan facilita a visualização e aponta onde estariam os problemas em cada contrato, na carteira de contratos e na empresa como um todo.

D. Qual é o nível dos clientes?

O Cubo Plan hoje opera efetivamente apenas dentro da Tetra Arquitetura. O resultado tem sido bastante satisfatório para o desenvolvimento esperado da empresa. Daí uma das motivações para se desenvolver o sistema.

E. Como funcionaria o esquema de distribuição do Cubo Plan?

A tendência é a distribuição via uso por licenças compradas por usuário, através de compra via e-commerce. Porém, encontra-se em desenvolvimento o planejamento das vendas.

F. A quem deve satisfazer?

Ao gestor da empresa que busca uma visão global da empresa em tempo real, gerenciando os riscos e benefícios, aos coordenadores, que terão um instrumento de visualização de recursos financeiros e humanos ao longo do tempo, e aos colaboradores, que poderão apropriar suas horas e visualizar uma série de informações importantes. Interessa principalmente ao corpo diretivo da empresa, que consegue visualizar os status dos projetos, suas receitas e despesas.

G. O que o cliente espera que aconteça com o resultado do Cubo Plan?

Centralizar informações dos projetos de arquitetura em uma única ferramenta, para que possa facilitar a vida dos funcionários, trazendo mais produtividade às implantações dos projetos, com a avaliação financeira do seu desempenho. Um dos resultados mais relevantes tem a ver com a mudança da maneira de gerenciar as empresas de arquitetura e engenharia civil.

H. Quem tomará as decisões e como acontecerão?

A Tetra Arquitetura possui três sócios majoritários que se reúnem em um conselho com mais quatro sócios para a tomada das principais decisões. 


\section{CUBO PLAN}

\section{Pesquisa 1 - Análise de satisfação do funcionário da empresa com a ferramenta Cubo Plan}

Foram realizadas entrevistas com quatro funcionários da empresa Tetra Arquitetura, utilizando-se um roteiro com perguntas padronizadas. Todos responderam com base na experiência apenas com o Cubo Plan, pois não conheciam outro ERP de mercado. Como resultado, foram identificados os seguintes aspectos:

- Todos se manifestaram positivamente quanto ao desempenho do sistema Cubo Plan.

- Consideraram não ser uma ferramenta engessada.

- A maioria deles acredita que a ferramenta traz mais produtividade ao trabalho.

- Entendiam que a ferramenta estava pronta para comercialização, com a indicação de melhorias necessárias.

- Operação simples e de fácil utilização, com potencial de facilitar a gestão do trabalho de arquitetos.

\section{Pesquisa 2 - Análise do}

desempenho de outras ferramentas concorrentes do Cubo Plan

As aplicações das ferramentas de ERP são muito abrangentes, com soluções para diversos negócios e tamanhos de empresas, com a possibilidade de se selecionarem as áreas da empresa a serem envolvidas, tais como vendas, financeira, clientes, projetos, compras, fiscal, contabilidade, manufatura e estoque. Em muitos casos é necessário customizá-las para necessidades específicas.

O foco da pesquisa sobre ferramentas de ERP disponíveis no mercado foi descobrir alguma opção que estivesse alinhada às necessidades de gestão e particularidades de processo comuns em uma empresa de projetos de arquitetura e engenharia civil, mas que fossem potenciais concorrentes ao software Cubo Plan. Os seus desempenhos foram comparados com os principais itens avaliados pelos tomadores de decisão, conforme mostra o Quadro 1. 
EDUARDO VELO DE OLIVEIRA, GUSTAVO ANDRÉ MATEUS VAZ DE LIMA, SAMUEL AGUIAR DE CASTRO E SOUZA, REYNALDO CAVALHEIRO MARCONDES, MARCUS PAULO LINARES RODRIGUES, GLAUBER RODRIGUES PEREIRA

\begin{tabular}{|c|c|c|c|c|c|c|}
\hline ERP & $\begin{array}{l}\text { Versão } \\
\text { em } \\
\text { Cloud }\end{array}$ & $\begin{array}{l}\text { Customização } \\
\text { de Projetos de } \\
\text { Arquitetura }\end{array}$ & $\begin{array}{l}\text { Complexidade } \\
\text { para Implantação }\end{array}$ & $\begin{array}{l}\text { Customização } \\
\text { Adicional }\end{array}$ & Custo & Fonte \\
\hline $\begin{array}{l}\text { ERP Cigam } \\
\text { Lumic } \\
\text { Consultoria }\end{array}$ & Não & Alta & Baixa & Não & Médio & $\begin{array}{l}\text { http://www.lumic. } \\
\text { com.br/arquitetura- } \\
\text { engenharia-sistema- } \\
\text { gestao }\end{array}$ \\
\hline Tulipa & Sim & Média & Baixa & Não & Baixo & $\begin{array}{l}\text { https://tulipaerp.com. } \\
\text { br/ }\end{array}$ \\
\hline Mega & Sim & Média & Média & Sim & Médio & $\begin{array}{l}\text { http://www.mega. } \\
\text { com.br/construcao/ }\end{array}$ \\
\hline Totvs & Sim & Alta & Alta & Sim & Alto & $\begin{array}{l}\text { https://www.totvs. } \\
\text { com/software-de- } \\
\text { gestao/construcao-e- } \\
\text { projetos }\end{array}$ \\
\hline Cubo Plan & Não & Alta & Baixa & Sim & Baixo & \\
\hline
\end{tabular}

QUADRO 1 - Comparação entre ERP

Fonte: Elaborado pelos autores.

\section{Pesquisa 3 - Análise do ponto de vista de outros arquitetos e engenheiros}

Foram realizadas entrevistas com profissionais de arquitetura e engenharia civil, com atuação destacada no mundo profissional, para conhecer os seus pontos de vista, considerando estarem utilizando outras ferramentas de gestão de projetos, independentemente de se tratar de um ERP ou não. Segue o resultado da pesquisa.
Arquiteta AP:

- Usava a ferramenta PowerWise para gerar a planilha que todos tinham que atualizar:

$<$ https://www.powerwisesystems.com/ building-management-systems/>.

- Apesar do PowerWise e das ferramentas fornecidas pelos clientes, todos os arquitetos do seu escritório tinham a planilha própria de gestão que atendia as suas necessidades.

- Contudo, o mesmo conteúdo estava sempre disperso por três locais diferentes. 


\section{Engenheiro MD:}

- Utilizava uma planilha Excel de gestão de projetos há muito tempo.

- Nunca usou ERP para seus trabalhos.

- Não sentia a necessidade de ERP para desenvolver projetos e contratos de engenharia civil e arquitetura.

\section{Engenheiro CM:}

- Usava a ferramenta Sienge, porém de maneira tímida, apenas para tarefas administrativas, mas com a expectativa de que fosse utilizada por todos na empresa.

- Tomou conhecimento da Cubo Plan por meio de um amigo da área de TI que trabalhava com várias empresas de engenharia civil que utilizavam o Sienge: $<$ http://www.sienge.com.br/>.

- Trata-se de um sistema completo que abrange todos os setores.

Engenheiro VS:

- Nunca usou ERP para gestão.
- Sentia a necessidade de ERP para desenvolver projetos e contratos de engenharia civil e arquitetura em sua empresa.

- Ele próprio realizava todos os controles na empresa.

\section{Aplicação do Canvas}

Foi utilizado o modelo Canvas para se entender com mais clareza e de maneira mais integrada o cenário da oportunidade de crescimento do Cubo Plan. Como resultado, foram identificadas outras oportunidades para geração de receitas utilizando o Cubo Plan, por meio de parcerias com empresas que desenvolvem projetos sociais e urbanos de grande repercussão.

A Figura 1 ilustra o que foi levantado com este modelo de desenvolvimento de negócios. 


\begin{tabular}{|c|c|c|c|c|c|}
\hline $\begin{array}{l}\text { Parcerias Principais } \\
\text { ONG's e entidades de } \\
\text { desenvolvimentos de negócios e } \\
\text { projetos sociais (ARTEMISIA - } \\
\text { CHOICE - YUNNUS) } \\
\text { Revistas especializadas de } \\
\text { Arquitetura. (CASA VOGUE - } \\
\text { HABITARE - CONSTRUÇÃO \& DESIGN } \\
\text { - REVISTA D\&A) } \\
\text { CAU-SP } \\
\text { Empresa de programação e } \\
\text { desenvolvimento de SOFTWARE. } \\
\text { Universidades e cursos especificos } \\
\text { de arquitetura. }\end{array}$ & $\begin{array}{l}\text { Recursos Principais } \\
\text { Relações Publicas para posicionar a } \\
\text { presa na mídia, visandoa a } \\
\text { propão da solução. } \\
\text { Pessoas ou Departamentos que } \\
\text { atuam diretamente com os projetos } \\
\text { educacionais. } \\
\text { Equipe exclusiva de apoio e } \\
\text { manutenção da ferramenta. } \\
\text { Servidor. }\end{array}$ & \multicolumn{2}{|c|}{$\begin{array}{l}\text { Propostas de Valor } \\
\text { empresas de arquitetura, com } \\
\text { linguagem e soluções focadas em } \\
\text { pequenas e médias empresas de } \\
\text { arquitetura, ofertando estrutura de } \\
\text { gestão segmentada ao mercado de } \\
\text { arquitetura. } \\
\text { Possuirá espaço para } \\
\text { desenvolvimento colaborativo, além } \\
\text { de foco para projetos sociais, } \\
\text { aumentando a utilizaçăo da } \\
\text { ferramenta, e a percepção de valor } \\
\text { do mercado. }\end{array}$} & $\begin{array}{l}\text { Relacionamento } \\
\text { com Clientes } \\
\text { Plataforma colaborativa, onde } \\
\text { arquitetos independentes possam } \\
\text { contribuir com "dicas" de otimização } \\
\text { da ferramenta. } \\
\text { Patrocinio de projetos sociais de } \\
\text { arquitetura (testando a ferramenta } \\
\text { em trabalhos realizados por } \\
\text { arquitetos que atuam em ONG'se } \\
\text { projetos sociais), e visitas em eventos } \\
\text { do setor. }\end{array}$ & $\begin{array}{l}\text { Segmentos de Clientes } \\
\text { O público possui demandas, muitas } \\
\text { vezes, especificas, mas encontram } \\
\text { ferramentas "massificadas" e } \\
\text { genéricas, que não atendem suas } \\
\text { necessidades e expectativas, e ONG's } \\
\text { de PROJETOS DE DESENVOLVIMENTO } \\
\text { URBANO E SOCIAL. } \\
\text { Empresas de arquitetura } \\
\text { (inicialmente, foco em pequenos e } \\
\text { médios escritórios) que não possuem } \\
\text { ferramentas otimizadas para sua } \\
\text { gestão. }\end{array}$ \\
\hline $\begin{array}{l}\text { Estrutura de Custos } \\
\text { Equipe de manutenção e ir } \\
\text { Equipe especializada para a } \\
\text { Contrapartida destinada ao }\end{array}$ & $\begin{array}{l}\text { parceiros (taxas, comissões, assinatura } \\
\text { patrocinio). } \\
\text { Custo mensal para servidor. }\end{array}$ & Iara publicação, & Red & $\begin{array}{l}\text { nio de outras entidades que queiram apa } \\
\text { nercado, apoiando a "causa social" e dese } \\
\text { Recebimento da comercializaça }\end{array}$ & $\begin{array}{l}\text { erramenta e integrações de } \\
\text { recer "positivamente" junto ao } \\
\text { nvolvimento acadêmico. } \\
\text { do software. } \\
\text { inaturas mensais. }\end{array}$ \\
\hline
\end{tabular}

FIGURA 1 - Canvas com os elementos constituintes

Fonte: Elaborada pelos autores.

\section{Aplicação do ciclo PCDA e da análise Swot}

Com o objetivo de identificar os pontos fortes e fracos do Cubo Plan, foram aplicadas integradamente as técnicas Swot e PCDA, de maneira a se ter um quadro mais completo do novo negócio da Tetra Arquitetura. Seguem os resultados, incluídas também as sínteses das oportunidades e ameaças, tratadas anteriormente:

\section{Oportunidades:}

- Possibilidade de atender a uma demanda que não estava sendo atendida completamente.

- Criar valor pelo aumento da produtividade na gestão do dia a dia dos negócios de arquitetura e engenharia civil, bem como de profissionais autônomos.

- Realizar parcerias de fornecimento com empresas que fazem projetos especiais de arquitetura.

- Realizar parcerias com projetos sociais e de urbanização. 


\section{Ameaças:}

- Concorrência de empresas que já estão no mercado, com ofertas de ERP com desempenhos bem próximas ao Cubo Plan.

- Risco de arquitetos e engenheiros não se adaptarem ao Cubo Plan, preferindo continuar utilizando o Excel, caso não percebam o valor criado por esse sistema.

- Os clientes não conseguirem avaliar adequadamente a relação custo $x$ benefício como favorável a eles.

- Startups poderem criar uma ferramenta cloud concorrente, com plataforma de grande porte, e investindo em barreiras no mercado para esse novo produto. Forças:

- O Cubo Plan é sistema estruturado especificamente para a arquitetura e a engenharia civil.

- Equipe que desenvolveu o produto tem conhecimento das principais necessidades do mercado, quanto à gestão de contratos e projetos de arquitetura.

- Fácil entendimento e didática para utilização da ferramenta.

- Cubo Plan tem preço acessível para aquisição por pequenas e médias empresas.

\section{Fraquezas:}

- Sistema ainda necessita incorporar melhorias que só virão com a sua prática, tendo o tempo contra.

- Empresa ainda não tem a estrutura adequada para venda de licenças.

\section{PROPOSTA DE APROVEITAMENTO DA OPORTUNIDADE}

A proposta de aproveitamento da potencial oportunidade da oferta do Cubo Plan teve como primeira etapa iniciar a homologação da ferramenta Cubo Plan com parceiros da Tetra Arquitetura. Essa medida visou identificar as dificuldades de aceitação e implementação em outros escritórios. Contribuiu também para apontamento de possíveis falhas que o sistema possa conter ou vir a apresentar.

Em seguida foi criada uma empresa com CNPJ e desenvolvido um portal de e-commerce como para o cadastro de clientes e porta de entrada para a geração de fonte de receitas com a venda das licenças. Também foi criado um portal para o pagamento da licença via internet com cartões de débito e crédito, para o cliente utilizar o Cubo Plan on-line. 
Foi feita uma versão trial para que potenciais clientes possam utilizá-lo gratuitamente por um período de tempo para testarem o desempenho da ferramenta. Com isso, fica mais fácil para eles se familiarizarem com o Cubo Plan e efetivarem a compra oficial da licença.

O desenvolvimento do mercado contempla ações de marketing e divulgação da ferramenta entre os profissionais do mercado de arquitetura e engenharia civil.

\section{Plano das principais ações de mudança}

Para garantir o sucesso na implantação do Cubo Plan no mercado foram estabelecidas ações, detalhadas no Quadro 2.

\begin{tabular}{|c|c|c|c|c|c|c|}
\hline Ação & Como & Responsável & Envolvidos & Prazos & Áreas & Custos \\
\hline $\begin{array}{l}\text { Criação do Site } \\
\text { E-commerce } \\
\text { responsivo para PC, } \\
\text { Mobile e Tablet }\end{array}$ & Desenvolvimento de TI. & $\begin{array}{l}\text { Web Designer } \\
\text { Tetra }\end{array}$ & $\begin{array}{l}\text { Diretoria e } \\
\text { Web } \\
\text { Designer }\end{array}$ & $03 / 12 / 2016$ & TI & $\mathrm{R} \$ 2.000,00$ \\
\hline $\begin{array}{l}\text { Precificação da } \\
\text { Licença }\end{array}$ & $\begin{array}{l}\text { Setor Financeiro deverá } \\
\text { precificar com base nos } \\
\text { estudos de valores de } \\
\text { mercado. }\end{array}$ & $\begin{array}{l}\text { Gerente } \\
\text { Financeiro }\end{array}$ & $\begin{array}{l}\text { Financeiro e } \\
\text { Diretoria }\end{array}$ & $22 / 11 / 2016$ & Financeiro & $\begin{array}{l}\text { Sem custo } \\
\text { adicional }\end{array}$ \\
\hline $\begin{array}{l}\text { Criação da Chave de } \\
\text { Segurança }\end{array}$ & Desenvolvimento de TI. & $\begin{array}{l}\text { Web Designer } \\
\text { Tetra }\end{array}$ & Diretoria & $03 / 01 / 2017$ & TI & $\mathrm{R} \$ 2.000,00$ \\
\hline $\begin{array}{l}\text { Termo de } \\
\text { confidencialidade }\end{array}$ & $\begin{array}{l}\text { Desenvolvimento do } \\
\text { Jurídico. }\end{array}$ & $\begin{array}{l}\text { Advogado } \\
\text { Tetra }\end{array}$ & Jurídico & $05 / 11 / 2016$ & Jurídico & $\begin{array}{l}\text { Sem custo } \\
\text { adicional }\end{array}$ \\
\hline $\begin{array}{l}\text { Implantação Piloto } \\
\text { em cinco Parceiros }\end{array}$ & $\begin{array}{l}\text { Reuniões de Parcerias e } \\
\text { acordos para utilização } \\
\text { da Cubo Plan. }\end{array}$ & $\begin{array}{l}\text { Marketing e } \\
\text { Diretoria }\end{array}$ & $\begin{array}{l}\text { Marketing e } \\
\text { Diretoria }\end{array}$ & $02 / 12 / 2016$ & Diretoria & $\begin{array}{l}\text { Sem custo } \\
\text { adicional }\end{array}$ \\
\hline $\begin{array}{l}\text { Desenvolvimento do } \\
\text { Mercado }\end{array}$ & $\begin{array}{l}\text { Ação de Marketing e } \\
\text { Relacionamento com } \\
\text { potenciais clientes. }\end{array}$ & Marketing & $\begin{array}{l}\text { Marketing e } \\
\text { Diretoria }\end{array}$ & $05 / 07 / 2016$ & Marketing & $\begin{array}{l}\mathrm{R} \$ \\
50.000,00\end{array}$ \\
\hline $\begin{array}{l}\text { Dar andamento às } \\
\text { melhorias do ERP }\end{array}$ & $\begin{array}{l}\text { Em paralelo ao projeto } \\
\text { piloto, realizar as } \\
\text { melhorias do ERP em } \\
\text { novas versões. }\end{array}$ & $\begin{array}{l}\text { Desenvolvedor } \\
\text { do ERP Cubo } \\
\text { Plan }\end{array}$ & $\begin{array}{l}\text { TI e } \\
\text { Funcionários } \\
\text { Tetra }\end{array}$ & $02 / 02 / 2017$ & TI & $\mathrm{R} \$ 5.000,00$ \\
\hline
\end{tabular}

QUADRO 2 - Plano de ações para o lançamento do produto no mercado

Fonte: Elaborado pelos autores. 


\section{Matriz de avaliação de riscos}

Espera-se que o Cubo Plan se posicione no mercado com potencial de agregar valor a nichos especiais (arquitetura e engenharia civil) onde hoje os profissionais reconhecem estar com baixa produtividade. Contudo, há riscos que precisam ser considerados, conforme apresentados no Quadro 3.

\begin{tabular}{|c|c|c|c|}
\hline Risco & Probabilidade & Impacto & Ação Corretiva \\
\hline $\begin{array}{l}\text { Profissionais de arquitetura e } \\
\text { engenharia civil não se } \\
\text { adaptarem à ferramenta } \\
\text { (Mudança de Cultura no } \\
\text { Mercado) }\end{array}$ & Média & $\begin{array}{l}\text { Alto } \\
\text { Projeto não ser implantado } \\
\text { com sucesso }\end{array}$ & $\begin{array}{l}\text { Buscar com urgência as } \\
\text { melhorias que se adaptem às } \\
\text { necessidades dos arquitetos e } \\
\text { engenheiros para aceitarem a } \\
\text { ferramenta. }\end{array}$ \\
\hline $\begin{array}{l}\text { Profissionais de arquitetura e } \\
\text { engenharia civil não aceitarem os } \\
\text { pagamentos pela ferramenta }\end{array}$ & Média & $\begin{array}{l}\text { Alto } \\
\text { Projeto não ser implantado } \\
\text { com sucesso }\end{array}$ & $\begin{array}{l}\text { Buscar investidores que } \\
\text { possam realizar mais ações de } \\
\text { marketing para conquistar a } \\
\text { confiança dos clientes e } \\
\text { revisar se os valores estão } \\
\text { alinhados com o mercado. }\end{array}$ \\
\hline $\begin{array}{l}\text { Ferramenta ERP não suportar a } \\
\text { quantidade de usuários } \\
\text { conectados ao mesmo tempo. }\end{array}$ & Baixa & $\begin{array}{l}\text { Médio } \\
\text { Lentidão na ferramenta }\end{array}$ & $\begin{array}{l}\text { Revisão da infraestrutura de } \\
\text { TI para suportar a ferramenta } \\
\text { on-line com maior } \\
\text { quantidade de acessos. }\end{array}$ \\
\hline Pirataria da ferramenta & Alta & Baixo & $\begin{array}{l}\text { O download da ferramenta é } \\
\text { para a tela inicial, porém, } \\
\text { grande parte do sistema está } \\
\text { na nuvem, ou seja, a pirataria } \\
\text { não permite acesso ao } \\
\text { principal serviço do ERP, que } \\
\text { não estará em mídia. }\end{array}$ \\
\hline
\end{tabular}

QUADRO 3 - Matriz de avaliação de riscos do produto Fonte: Elaborado pelos autores. 


\section{CONSIDERAÇÕES FINAIS E CONTRIBUIÇÕES}

Os pontos de aprendizado mais relevantes na realização deste trabalho têm a ver com a análise das necessidades do mercado, a gestão de projetos de maneira produtiva $\mathrm{e}$ o desenvolvimento da ferramenta por quem a utilizava, na Tetra Arquitetura. O foco básico foi entender o valor que a solução do Cubo Plan criaria para a gestão dos negócios de arquitetura e engenharia civil, de maneira a adequar essa ferramenta para oferecer um valor diferenciado e superior aos seus potenciais usuários.

Outro ponto de aprendizado foi constatar a utilidade e praticidade de técnicas e ferramentas como o Brainstorm junto à equipe interna, que já utilizava o programa há algum tempo, o Canvas, o ciclo PDCA, a análise Swot, o plano das principais ações e a matriz de avaliação de riscos, para poder assumir que o ERP/CRM Cubo Plan tem potencial para auxiliar na melhoria da gestão administrativa de empresas de projeto de arquitetura e engenharia civil.

Não obstante este relato ter tratado de uma situação única, entende-se que a sua contribuição esteja em mostrar a importância de se ter uma lógica metodológica para dar consistência à proposição de um novo negócio.

\section{PROJECT MANAGEMENT OF ARCHITECTURE AND ENGINEERING WITH CUSTOMIZED ERP/CRM CUBO PLAN}

\section{ABSTRACT}

This report presents the development of the Cubo Plan ERP / CRM system of the company Tetra Arquitetura that identified as a market opportunity, to meet the demands of offices of architecture and civil engineering projects, to offer a tool to generate integrated information and able to follow and evaluate the performance of their business. The lack of specific information tools for managing the company itself resulted in the development of a system to improve the effective control of its processes. In fact, the information to guarantee the efficiency of the projects executed by the company, were distributed by diverse bases and platforms, causing a high volume of work in something that was not its core business, harming the decision making. Thus, it was based on the internal experience with the use of the tool, to then offer it to the market of architectural and civil engineering projects, giving rise to a new business. This report presents the details of what was done to develop and launch the ERP / CRM system 
Cubo Plan as a differentiated product in the market, based on a methodology for the production of practical and applied works.

\section{KEYWORDS}

ERP/CRM. Project management. Management system. Cubo Plan.

\section{REFERÊNCIAS}

CHRISTENSEN, C. M.; RAYNOR, M.; MCDONALD, R. Mais uma vez: o que é inovação disruptiva? Harvard Business Review, p. 44-53, dez. 2015.

FRANKLIN, M. A.; BARRAL, J. G.; SILVA, L. R.; PEREIRA, M. F. T.; PIANUCCI, M. C.; PINTO, B. O. C. Inovação e a sustentabilidade sob a dimensão social: do discurso à ação - um estudo empírico em uma empresa paulista do ramo frutífero. Revista Brasileira de Gestão e Desenvolvimento Regional, v. 12, p. 276-300, 2016.

FRANKLIN, M. A.; MEIRELLES, S. D. Figura do ator integrador no gerenciamento da inovação em rede de PMEs: um estudo de caso. In: SIMPÓSIO DE GESTÃO DA INOVAÇÃO TECNOLÓGICA, 2006, 24., 2006, Gramado. Anais... Gramado: Anpad, 2006.
KAPLAN, R.; NORTON, D. A estratégia em ação - balanced scorecard. Rio de Janeiro: Campus, 1997.

MACHADO, D. D. P.; VASCONCELLOS, M. A. Organizações inovadoras: estudo dos elementos de um ambiente inovador. In: SIMPÓSIO DE ADMINISTRAÇÃO DA PRODUÇÃO, LOGÍSTICA E OPERAÇÕES INTERNACIONAIS, 7., 2004, São Paulo. Anais... São Paulo, 2004.

MARCONDES, R. C.; MIGUEL, L. A. P.; FRANKLIN, M. A.; PEREZ, G. Metodologia para elaboração de trabalhos práticos e aplicados: administração e contabilidade. São Paulo: Editora Mackenzie, 2017.

McCAFFREY, T.; PEARSON, J. A inovação está onde você menos espera. Harvard Business Review, dez. 2015. Disponível em:<http://hbrbr.uol.com.br/a-inovacaoesta-onde-voce-menos-espera/>. Acesso em: 20 jan. 2017.

MIGUEL, L. A.; FRANKLIN. M. A.; POPADIUK, S. The knowledge creation with view to innovation as a dynamic capability in competitive firms. Journal of Academy of Business and Economics, v. 8, n. 4, p. 45-56, 2008. 
OLIVEIRA, S. M.; ALVES, J. L. Influência das práticas de inovação aberta na prospecção de conhecimentos para a criação de valor em ambientes de alta complexidade sob condições de incerteza e imprevisibilidade. Revista de Administração e Inovação, São Paulo, v. 11, n. 1, p. 295-318, jan./mar. 2014. PISANO, G. P. Você precisa de uma estratégia de inovação. Harvard Business Review, fev., 2016

SAMBIASE, M. F.; FRANKLIN, M. A.; TEIXEIRA, J. A. Inovação para o desenvolvimento sustentável como fator de competitividade para as organizações: um estudo de caso Duratex. Revista de Administração e Inovação, v. 10, n. 2, p. 144168, abr./jun. 2013.

SCHERER, F. O.; CARLOMAGNO, M. S. Gestão da inovação na prática: como aplicar conceitos e ferramentas para alavancar a inovação. São Paulo: Atlas, 2009.

SILVA, A. A.; FRANKLIN, M. A.; FERREIRA, A. F.; MARTINI, F. S.; BACCARIN, G. O. A influência do ambiente organizacional na inovação de produtos em empresas empreendedoras. In: ENCONTRO DE ESTUDOS SOBRE EMPREENDEDORISMO E GESTÃO DE PEQUENAS EMPRESAS, 5., 2008, São Paulo. Anais... São Paulo: Anegepe, 2008.
TIDD, J.; BESSANT, J.; PAVITT, K. Gestão da inovação. Porto Alegre: Bookman, 2008.

TIGRE, P. B. Gestão da inovação: a economia da tecnologia do Brasil. Rio de Janeiro: Campus, 2006.

WOODRUFF, R. B. Customer Value: The Next Source of Competitive Advantage. Journal of the Academy of Marketing Science, v. 25, n. 2, p. 139-153, 1997.

ZEITHAML, V. A. Consumer perceptions of price, quality, and value: a means-end model and synthesis of evidence. Journal of Marketing, v. 52, n. 3, p. 2-22, 1988. 